\title{
REPORT
}

$O N$

\section{S UGAR BEETS,}

Raised upon the Faril of the

Massachusetts Agricultural College.

\section{By CHARLES A. GOESSMANN, Pr. D.,}

Professor of Chemistry.

Reprinted from the Auerican Chemist.

NEW YORK:

S. Axafll, Printer, 410 Fourtu Av. 


\title{
REPORT
}

\author{
ON

\section{S UGAR B E E T ,} \\ Raised upon the Farm of the
}

Massachusetts Agricultural College.

By Charles A. GoessmanN, Pr. D., Professor of Chemistry.

Reprinted from the American Cuemist.

NEW YORK:

$$
74384
$$

S. $\Lambda$ vaeli, Printer, 410 Fourtil $\Lambda v$.

1872. 
SB221

G 6 


\section{REPORT ON SUGAR-BEETS, RAISED UPON THE COLLEGE FARM.}

BY Charles A. GoessmanN, PH. D.

Professor of Chemistry in the Mass. Agricultural College

In a previous report, $*$ I expressed the opinion, that the profitable cultivation of the sugar-beet for the manufacture of sugar, must depend, if not exclusively, at least essentially, on the interest, which intelligent agriculturists will take:

First, in a careful selection of superior seeds of the best foreign varieties, and subsequently of the choicest seed-beets; and,

Second, in the proper choice of lands, which are not only well adapted to the cultivation of root crops in general, but also in such a state of fertility, as to enable the farmer to control the kind and the amount of plant food required for the production of a special crop, for special purposes, i. e. Sugar-beets for the economical manufacture of sugar. Considering these premises of first importance, I attempted a short exposition of the ways and the means, by which these requirements have been accomplished elsewhere, showing how farmers and manufacturers, by a mutual understanding, have contrived to promote their mutual interest, and that their great success was particularly due to the fact, that the former, in his legitimate attempts to produce a large crop, never failed to keep in mind, that the ultimate object was to secure a sugar-beet, which would contain the desired amount of sugar under advantageous conditions for its separation. He knew that the manufacturers would value every percentage of sugar about 2.4 cents, with more or less of the vegetable refuse of roots, and leaves returned. The history of the pioneers in the beet sugar industry in every country -ours not excepted-furnishes striking illustrations in that direction. German beet sugar manufacturers do not hesitate to ascribe their great success, over

* Sec American Chemist, Vol. 1, pp. 381-399. 
other competitors at the World's Exhibition at Paris in $\mathrm{I} 867$, to their superior sugar-beets.*

To transfer a known process of manufacture from one country to another, is a simple problem, and offers in skilled hands but little risk, in cases where the materials to be turned to account can be shown to be either identical, or to stand at least in some simple, fixed relation to those which have been previously used. Quite different, however, are the circumstances, when the introduction of an industrylike beet sugar manufacture-is contemplated, for a good sugar-beet is the result of the particular influence of peculiar modes of farming, of soil and of climate. To suspect a possible serious change in the composition of a sugar-producing plant like the sugar-beet, in consequence of a transfer of its seed from one country and soil to another, is but reasonable in view of our past experience concerning sugarcane* (sorghum $\dagger$ ), the cultivated grapes, and fruits of every description. The sugar-planters of Louisiana and of the West Indies, have to accommodate their modes of operation for the manufacture of sugar, to suit the peculiar condition of the same variety of cane they are cultivating; even upon the island of Cuba, planters cannot manage the details of their operations alike and expect to be equally successful. As the system of manuring, the kind of soil, and the depth and character of the sub-soil, in particular, besides certain conditions of the climate are known to exert a powerful influence on the quality, and thus on the fitness of the sugar beet for the manufacture of sugar, and as all these controlling influences vary more or less in different countries, it is quite plain that a series of well-designed and carefully-conducted experiments are desirable for the purpose of studying the behavior of a good imported sugar-beet seed upon our soil and under our climate; they are indis-

* In Germany the beet root is taxed-in France the beet sugar produced; which is a sufticient reason to account for the superiority of German machinery and skill.

+ See Notes on the Manufacture of Sugar in the Island of Cuba, by Charles A. Goessmann, Syracuse, N. Y., 1865.

¥ On Sorghum or Chinese Sugar Cane, by C. A. Goessmann, see Transactions of the $\mathbf{N} \mathbf{Y}$. State Agricultural Societ.y, 1860. 


\section{[5}

pensable as a reliable basis for the introduction of the beet sugar manufacture as a home industry.

Animated by these considerations and somewhat encouraged by the results of the preceding year, my examinations in the field and in the laboratory have been continued and enlarged upon during the past season. The results, which have been gratifying in both directions, will be described within the following pages. In view of the numerous questions which presented themselves as worthy of particular attention, a selection had to be made; I confined myself for obvious reasons to tbe following points:

First, to produce good sugar-beets in a sufficient quantity and in accordance with the rules laid down in my report for 1871 :

Secondly, to study the chemical properties of the sugar-beet raised upon the College Farm, with reference to their fitness for beet sugar manufacture;

Thirdly, to ascertain by actual tests the amount of sugar available for commercial purposes.

\section{I. -ON THE CULTIVATION OF THE SUGAR-BEET.}

The field selected for the cultivation of the sugarbeets consisted of four and seven-tenths (47) acres, which sloped gently towards the west; the soil was a warm sandy loam, with the exception of the southwest corner, which, being wet, was subsequently planted with various kinds of common Mangolds. Grass had been raised upon the land for several years, until the fall of 1869 , when it was plowed and a good coating of coarse yard manure put upon it. In the spring of 1870 it was planted with corn, each hill receiving a handful of a phosphate manure, and yielded 70 (seventy) bushels of corn per acre that year. It was thus, in consequence of a suitable selection of manure and a satisfactory preceding crop, in a desirable condition for the production of sugarbeets. During the spring of 1871 , the land was three times plowed, harrowed and rolled to make its mechanical condition as farorable as possible. The field was subsequently divided into five equal parts, running from east to west, conforming with its slope. Each of these divisions received, a few days before 
seeding, five hundred pounds of various commercial phosphates, which were sown broad-cast. The various kinds of seeds, which were imported during the last two years, had been previously tested in regard to their fitness for germination, and they all produced, after soaking a little in water, healthy young plants, within from seven to ten days. The following varieties and respective quantities were planted by means of Holbrook's seed-drill, the most suitable implement on hand:

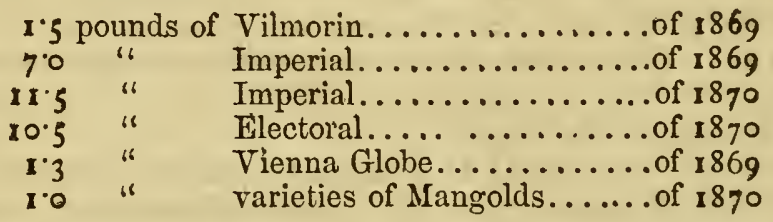

The rows were two and one-half ( $\left.2 \frac{1}{2}\right)$ feet apart and passed from north to south through each of the fertilizers. The planting of the seed took place on the I rth and I th of May, and on the 22d of May, the rows were distinctly marked by the young crop. The entire field looked well, with the exception of ferst few rows on the east side, where some troubles with the "seed-drill" had left empty spaces.

These spots were subsequently filled out with young plants from other parts of the field at the time when the surplus plants were taken out; after thinning, the plants stood from six to eight inches apart: During the time from the first of June until the twenty-first of July, the young plants were hoed three times, to keep the root-tops covered, and the space between the rows cultivated as many times with a horse-hoe to destroy the weeds. The whole crop looked promising during the entire season, with the exception of the transplanted beets, which remained behind in spite of an additional manuring, and confirmed the statement made in my previous report, that the general experience of beet sugar cultivators teaches, that it does not pay in. most cases to transplant; for these plants remain usually so far behind, that they are of no value for sugar manufacture. Towards the end of September the outẹr leaves began 
to dry up, indicating under normal circumstances the ripeness of the roots.

My examinations concerning the saccharine properties of the various kinds of beet-roots began at this time. The harvesting of the entire root-crop took place on the I 9 th and 20 th of October.

The danger of a serious frost rendered it advisable to protect the roots against its damaging influence; for this reason part of them were buried without delay after being carefully freed from the leaves, care being taken not to injure them. The pits were six by three feet wide and three feet deep, and were located upon the elevated side of the beetfield. The leaves had already somewhat suffered from the frost and were mostly dried up. The larger portion of them were on that account left upon the field to serve as mannre. A small quantity of leaves, still green, were, however, collected and buried in a pit of twelve feet long, three feet wide, and three deep, to be kept until spring for experimental purposes. The root crop averaged per acre twenty-two thousand two hundred $(22,200)$ pounds. This amount exceeds the produce in Silesia, and ranks with the usual results in Saxony. The results obtained upon the experimental field of the College farm may be looked upon as gratifying and encouraging, particularly, when we remember the reduction caused in the crop by the defective operation of the seed-drill and also keep in mind, that the entire operation of planting, etc., had to be managed with unsuitable implements. The rows of beets instead of being twenty inches apart with eight inches space between the plants, which would have secured from 28,500 to 30,000 plants, had to be kept two and one-half feet apart to allow the horse, and the cultivator on hand, to pass between the rows, causing a great waste of land. There are implements long used in the sugar-beet cultivation which locate the rows from I8 to 20 inches apart, and which are used both in seeding and in cultivating from four to eight rows at once. In view of this first actual yield, I believe that with suitable implements the annual produce of gugar-beet roots per acre would rank with the highest 
yield in Saxony, which is stated to be from thirty to thirty-two thousand $(32,000)$ pounds of roots per acre. In my original plan for the fertilization of the beet field, I designed to apply from 250 to 300 pounds of Stassfurt potash fertilizers per acre. The scarcity of these valuable potash compounds in our markets, when wanted, prevented their arrival at a sufficiently early date. Although a small strip ten feet wide in each of the fire main divisions of the field received finally some commercial Kainit at the rate previously mentioned, no particular importance will be attached to that fact. T'he sugar-beet is manifestly a potash plant, and the application of potash fertilizers but rational. Their good effect cannot be doubted, wherever the soil has been shown to be really deficient in available potash compounds and where time and the peculiar physical condition of the various layers of the soil have favored their penetration to the strata upon which the plant under cultivation mainly feeds. Oversight in regard to these important points may be considered as the cause of existing contradictory statements. To apply the Stassfurt fertilizers to meadow grasses or even to potatoes as a surface dressing or shortly before their planting may give satisfaction in most cases; for these plants live, comparatively speaking, largely upon the surface soil and their roots branch in every direction in search of food. The sugar-beet, on the other hand, sends by natural disposition, its main roots to the sub-soil ; the quality of which is, therefore, of great importance. The potash must descend to the sub-soil, as exact investigations of a more recent date demonstrate, before its beneficial effect* will be noticéd on plants like the sugar-beet. This circumstance explains, to some extent at least, the peculiar fact that potatoes and sugar-beets, although prëeminently potash plants, have been raised upon the same land for years in succession with very, satisfactory results, $\nmid$ and without showing

* 250 pounds each of Kainit and of Superphosphate per acre are highly recommended.

+ Potatoes were raised on a large scale to serre as an admixture to the beet molasses for alcohol manufacture, in order to render the refuse from the still of more value for feeding purposes. 
the usual sign of exhaustion which such a practice in most instances would soon produce. In connection with the investigation of the previous question, an interesting fact has been noticed, which deserves attention, particularly as it may lead to misconstructions.

It was demonstrated by careful experiment (Frank) that a small percentage of the chloride of sodium aids in the circulation of the potassa compounds in the soil, acting in that respect similar to the nitrate of soda, and apparently counteracting the ordinary retentitiveness of the soil and favoring the passage of the potassa to the sub-soil. The chloride of potasslum and the sulphate of potassa are alike readily decomposed in a good soil. The potassa is always very eagerly retained in the surface portion of a soil of good physical condition, and passes only gradually to lower depths, provided the soil has not received an unusually large supply, and is not too inferior in retentive quality. It takes months usually before its surplus will reach the lower strata, and the rate of its downward motion depends entirely on the chemical and physical condition of the soil. Chlorine and the mineral acids, with the exception of phosphoric acid, differ essentially in that respect and pass on more rapidly to the drainage waters.

The demand for chlorine is limited; not more than 0.08 per cent. of the amount introduced by the application of chloride of potassium being absorbed by sugar-bect roots. The absence and the presence of chloride in the mineral fertilizers affects the root crop but slightly, provided a sufficient amount of potash is supplied, and the chloride of sodium not used in excessive quantity. Wherever potash is wanting and at the same time common salt is largely supplied as a fertilizing agent, it is but natural that the sugarbeet should manifest a tendency to return to its more primitive form, the common fodder beét. The recommendation of the direct application of the Stassfurt salines for fertilizing purposes in the case of the sugar-beet will appear, to many readers of my report "On Beet Sugar Cultivation" for $187 \mathrm{I}$, of rather doubtful merit, and apparently somewhat in contra- 
diction with previous statements. They will remem ber in all probability the objection raised against the selection of lands, which, from natural causes, contain a large accumulation of the various saline constituents of plant resulting from the decay of successive generations of vegetation, as wood-lands and prairie-lands but recently put under cultivation. These lands are not fit in their original state, it is true, for the cultivation of a good sugar-beet, because their mineral elements find more than their equivalent of suitable organic, and particularly of nitrogenous plant food, which favors a luxuriant growth altogether different from what the beet sugar minufacturer desires. Large quantities of nitrogenous and non-nitrogenous compounds, peculiar to this species of the plant, enter it and carry their corresponding quantity of mineral constituents with them, which, of course, will also be present in an extraordinary amount. These very same lands, if of a more sandy than clayey nature with a permeable, sub-soil may prove in consequence of repeated cropping sooner or later a most excellent soil for the cultivation of the sugar-beet. It is after all a good physical condition of the soil, which in the hands of an intelligent farmer will most surely in the course of time turn the scale of profit in his favor. Silesia, where the beet sugar husbandry of Europe originated, falls in. spite of equal skill and perseverance considerably behind other districts in its average-yield of roots per acre in consequence of a less favorable soil. Neither much exhausted lands nor such as above described offer encouraging prospects for a first trial of the beet sugar industry. No sugar-beet can be raised without potash or without phosphoric acid, and the same may be said about some of the other constituents, though we rarely call attention to this fact; because the natural supply is usually sufficient. Soda in case of a deficiency of potassa will serve to a limited extend, as a substitute; sulphuric acid may replace in the same way phosphoric acid and magnesia the lime; but neither of the various constituents alone stand in any fixed relation to the per cent. of sugar, except the potash or rather the sum of alkalies. (Stohmann). 
II. ON THE QUALITT OF THE SUGAR-BEETS RAISED.

A good sugar-beet has the following properties; its leaves are numerous, of medium size, not upright, but rather rounded and drooping and of uniform, light green color; its root is of moderate size, not exceeding two and one half pounds; the skin of the root is smooth and white, and its meat, hard, white, and of sweet taste. The form of the root is pear, or wedge shaped, very gradually terminating in a long thin tap root without any side branches; its specific gravity is always less than that of its juice. The specific gravity of a good sugar-beet varies, in the majority of cases, between I.010 and I'060; though instances are on record where it was found to be as high as $1 \cdot 070$. Roots between one and two pounds in weight contain usually a juice of less density and also frequently of less value, than those of one half a pound or even less weight, and similar conditions have been noticed in regard to their relative proportions of sugar and their other remaining soluble constituents. Roots of a higher specific gravity contain usually less of these latter constituents in their juice, and their quantity varies within quite narrow limits, from 2.0 to 2.7 per cent.; whilst the juice of roots of a lower specific gravity, usually contains not only more impurities, but what is of particular importance, because of a more general occurrence, these foreign soluble substances are present in much larger quantities, namely, from 2.7 to $5^{\circ} \circ$ per cent. and more. The following two facts will be apparent from the previous statements; namely, that no strictly reliable deduction can be drawn from the specific gravity of the sugarbeet root in regard to the value of its juice; nor from the specific gravity of the juice to that of its per cent. of sugar, beyond the general assumption that in most cases the larger roots (from 2 to 3 lbs.) of the same quality of sugar-beets are inferior to the smaller specimens. Individual roots of the same variety raised upon the same piece of land and under the same treatment, even when of the same size are known to differ in regard to their composition as far as their saccharine quality is concerned. (Stammer). The quality 
of a sugar-beet crop, therefore, can only be safely decided by testing a large number of roots of various sizes from different portions of the field and accepting the mean of a series of such examinations as the most probable actual condition of the entire crop. All tests have to be made without any unnecessary delay; for beet roots, like other roots, lose moisture on exposure to the air, and suffer thereby more or less serious alteration, which, if not taken into consideration, must result in mistakes. 'The increased density of the juice

- will be followed by a correspondingly smaller yield. The loss noticed during an ordinary state of the atmosphere, amounted, at a temperature of from $15^{\circ}$ to $18^{\circ} \mathrm{C}$., to 2.6 per cent. within thirty hours, and to I $3^{\circ}$ I per. cent. within eight days; whilst at a temperature of $30^{\circ}$ to $40^{\circ} \mathrm{C}$., it reached 23 to 25 per cent. and the internal changes as far as the crystallizable sugar is concerned are in the latter case still more serious. A sound, fresh, full grown sugar-beet root is free firom grape sugar and from ammonia, yet both compounds will be noticed sooner or later in a beet root after its removal from the soil, and subsequent exposure to a temperature which favors fermentation. The practical sugar-beet cultivator recognises this fact by placing the roots, after their removal from the soil and their separation from the leaves, without much delay in pits. A lacerated beet decays rapidly. The beet roots raised upon the College farm, on the whole, showed the characteristics of good specimens, having in the majority of cases a smooth white skin and a white, hard, and sweet meat. They were remarkably compact; their form was good and branch roots of not frequent occurrence. The main bulk of these did not exceed one pound and a quarter (I 1 ) in weight; specimens from two to three pounds in weight were rather scarce. The outer leaves turned yellow towards the middle of September, indicating the ripeness of the roots. My laboratory tests for determining their per centage of sugar began on the loth of September.

1. Determination of the amount of acuter in the ronts.

$13.818 \mathrm{grammes}$ of carefully cut thin slices of the Imperial sugar-beet were loosely packed between 
given weight of dricd blotting paper and kept in an air-bath at a temperature from $100^{\circ}$ to $105^{\circ} \mathrm{C}$. until a constant weight was obtained; the loss amounted to I I 328 grammes or 8 I.98 per cent. of water; again 9.19I grammes of the same beet root were dricd under corresponding conditions; the loss amounted to 7.502 grammes or $81^{\cdot} 74$ per cent.

\section{Imperial Sugar-beet root.}

$\begin{array}{lrr} & \text { I. } & \text { II. } \\ \text { Non volatile matter } & 18 \cdot 02 & 18 \cdot 26 \\ \text { Water } & 81 \cdot 98 & 8 \mathrm{I} \cdot 74\end{array}$

A good sugar-beet contains usually from 81 to 82 per cent. of water, yet it may vary from 79 to 86.63 per cent. of water and from 13.37 to $21^{\circ} 0$ per cent. of dry substance.

2. Tests of the juice.

The juice of the roots, of the tops, and of the main parts of the leaves differ widely; an analytical statement concerning these points* will be found quite instructive here;-

M. Mehay. Juice of Root. Of Leaf Stalk. Of Leaf.

$\begin{array}{lcll}\text { Sugar, crystallizable } & \mathbf{1} 2.00 & 0.25 & 0.00 \\ \text { Sugar, non crystallizable } & 0.50 & 2.72 & \mathbf{1} .23 \\ \text { Oxalic acid } & 0.22 & 0.43 & \mathbf{I} 86 \\ \text { Specific gravity } & \mathbf{1} 060 & \mathbf{1 . 0 2 3} & \mathbf{1} .025\end{array}$

The sugar was determined by means of fermentation after Dubrunfaut's method.

Heidepriem, 1869 . Specific gravity Sugar

Soluble substances without sugar Organic substances without sugar Ashes-less carbonic acid Protein substances Sugar F. Stohmann, rsGog.

Soluble substances without sugar Potassa
Juice of the sugar- Jnice of beet root without tops. the tops.

$\begin{array}{lr}1.0648 & 1.0572 \\ 13.6800 & 10.2100 \\ 2.0200 & 3.3900 \\ 1.4600 & 2.4600 \\ 0.5600 & 7.200 \\ 0.887 & 1.7500\end{array}$

Sugar-Beet Juice

$\begin{array}{cr}\text { Minimum. } & \text { Maximum } \\ 9.56 & 17.680 \\ 0.3^{8} & 3.510 \\ 0.09 & 0.255\end{array}$

* Mehas: Compt. rend. t. LXIX. p. 754. Ileidepriem: Zeitschrift XIX. S. 75. Strhmann: Zeitschrift XIX.S. 273 ; see K. Stammer's Jahresbericht, I S6\%. 
The amount of other soluble substances for each Ico parts of sugar in the beet juice varies from 8.00 to I 8.50 parts.

The specific gravity of the beet juice is usually ascertained by Brix's saccharometer, an instrument which refers to percentages of pure sugar in distilled water. As the beet juice contains besides sugar a variety of organic and inorganic compounds, its indications are of interest only for comparative tests. The exact amount of dry substance in the juice has to be decided by a careful evaporation to dryness.

The percentage of sugar in the juice from the same beets may differ somewhat in consequence of different ways of obtaining it. The juice obtained by a centrifugal apparatus and that abstracted by hand were noticed to differ about 0.7 per cent., the latter being the richer juice; whilst that obtained by a powerful press may even exceed this by from o. I to 0.66 per cent. These few general remarks may serve to place some of mys subsequent analytical statements in their proper right.

\section{Determination of the sugar in the juice.}

Most of the sugar tests were made by means of an excellent Dubosq-Soleil's optical saccharometer. In some instances the results thus obtained have been verified after converting the entire amount of the cane sugar present intogrape-sugar ; in other cases, particularly where the Dubosq's apparatus gave high results, I verified the optical test by a chemical one by the use of Felling's well-known solution. The juice for my experiments was produced, where not otherwise directly stated, in the following way: a number of sugar-beet roots of various weights, which were collected from the five divisions of the beet-field, were freed from the tops as far as the leaf marks extended. The roots were subsequently ground by hand upon a common tin grater and the pulp resulting pressed by hand in a strong cloth. In a few instances, when a larger number of roots were to be pressed for juice, they were cut by an ordinary root-cutter and pressed in a common iron screw press. The juice after being obtained in either of these ways was either allowed to 
settle, or strained through a cloth and then tested in regard to its specific gravity by means of a Brix's saccharometer. The preparation of the juice for the test with the polariscope was carried out in the following way : 500 c.c. of the juice were filled into a graduated glass-cylinder, and subsequently thoroughly mixed with 50 c.c. of a solution of sub-acetate of lead of the usual concentration.* As soon as a light colorless solution began to separate from the bulky precipitate, the whole mass was put upon two filters of coarse paper and quickly filtered. The juice thereby obtained was again without delay filtered through I 50 c.c. of medium sized coarse bone-black. The first rco c.c. of the filtrate were set aside and the subsequent filtrate turned to account for the optical test in the usual manner.

I removed roo c. c. of the filtrate, its first portion, for the purpose of rendering the solution for the tests independent of the incidental influence of bone-black, (its moisture, etc.) This mode of proceeding was adopted to allow a direct comparison of my results with numerous other investigations of a similar character, and for similar ends. The polariscope was in each case adjusted with a carefully prepared standard solutiont of pure sugar and also with water; the number of degrees required to produce the optical effect of presenting but one color, were increased by one-tenth of their number to compensate for the dilution of the original genuine beet-juice by the lead solution used for its defecation; each degree represented 0.1635 per cent. of sugar. The results of my tests will be given in a chronological order; they refer mainly to sugar-beets and other beet-roots raised upon the College-farm; an appendix contains also a few tests concerning sugar-bects, etc. raised elsewhere in the state.

\footnotetext{
* Digest I part of acetate of lead, I part of oxide of lead, and 20 parts of water at $30^{\circ}$ to $40^{\circ} \mathrm{C}$, from 6 to io hours, anil filter.

+1050 c.c. water containing $163^{.50}$ grammes of pure sugar in solntion, when filled into a tube of $200 \mathrm{~m}$. m. length produces the same rotation as a quartz plate of one in. $m$. in thiekness; Ioo c.e. of water, containing 16.35 r. e. of pure sugar in solution, observed in a tube of $200 \mathrm{~m}$.m. lengtb indieates the percentage by means of degrees.
} 
Sugar-beets from the College-Farm.

Sept. 10, 1871. Electoral sugar-beet (Magdeburg), seed imported 1870,

Weight of Roots with top.

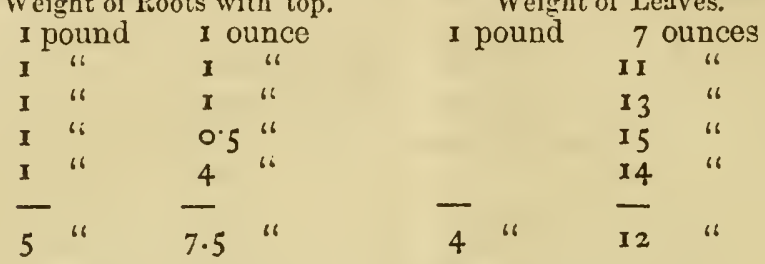

Juice; Brix $14^{\circ}$ at $17^{\circ} \mathrm{C}$. sugar $12 \cdot 30$ per cent.

Sept. 12. Imperial sugar-beets; seed imported 1870. Roots with top.

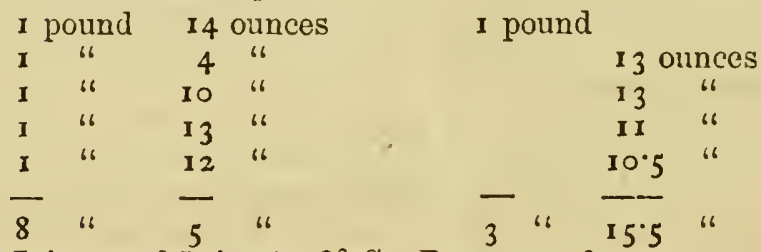

Juice; $15^{\circ}$ Brix at $18^{\circ} \mathrm{C}$. Per cent. of sugar 12.59.

Sept. 13. Fr rench Vilmorin beet; German seed imported 1370 . Roots with top.

$\begin{array}{llll}\text { I pound } & 9 & \text { ounces } \\ 2 & 66 & 4 & 66 \\ 1 & 66 & 5 & 66 \\ 1 & 6 & 5 & 66 \\ \text { I } & 6 & \text { I1 } & 6 \\ 7 & 6 & - & \end{array}$

Juice; $14.5^{\circ}$ Brix at $18.5^{\circ} \mathrm{C}$. per centage of sugar 12.95

Oct. IIth. Imperial beets; seed imported 1870 ; $250 \mathrm{lbs}$. of these roots, without tops, were cut by a common root cutter and pressed with an iron screw press; the roots were nooist from washing before cutting.

Juice; $15^{\circ}$ Brix at $22.5^{\circ} \mathrm{C}$. Sugar 12.05 per cent.

Oct. 16th. Electoral sugar-beets; seed imported 1871; 490 pounds of roots without tops cut by root cutter and pressed by an iron screw press.

Juice; $15^{\circ}$ Brix at $18^{\circ} \mathrm{C}$. Sugar $12^{\circ} 22$ per cent. 
Oct. I 8th. Vilmorin sugar-beets; seed imported 1870; 600 pounds of roots without tops cut by root cutter and pressed by an iron screw press.

Juice; $16^{\circ}$ Brix at $16^{\circ}$ C. Sugar $13^{\circ} \times 29$ per cent.

Nov. 14. Imperial beets, taken from the pit.

lioots with tops.

$x$ pound 8 ounces.

Leaves.

I 3.5 "

No leaves.

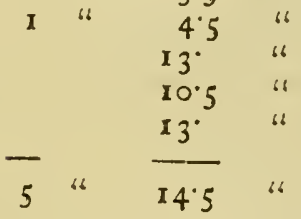

Juice (by hand press) $15^{\circ}$ Brix at $18^{\circ} \mathrm{C}$; $1.064-1.065$

spec. gravity; Sugar II.60 per cent.

Nov. 2I. Vilmorin bects; from the pit; one root with top, one pound I2 ounces; juice, $15.5^{\circ}$ Brix at $14^{\circ}$ C. ; Sugar 13.12 per cent.

Fodder-beets raised upon the College-Farm.

Sept. Ith. Irienna red-yellow and white globe-bect, Roots with top.

2 pounds 2 ounces.

\begin{tabular}{ccccc}
1 & 66 & 8 & 6 & 10 \\
\hline 6 & 6 & 1 & 6 & 10 \\
\hline 11 & 6 & 2 pounds.
\end{tabular}

Lenves.

12 ounces.

$10 \quad 6$

$\frac{3}{6}$ "

Juice; Brix $x x^{\circ}$ at $18.5 \mathrm{~V}$; Sugar 8.004 per 0.

Sept. I gth. Ordinary Mangolds (red and vellow); seeds sent from the National Agric. Department.

Roots with teps.

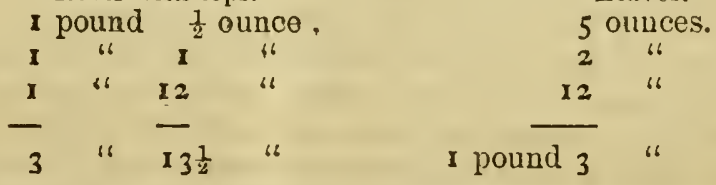

Juice; Brix $9^{\circ}$ at 19 C.; Sugar $5^{\circ} 035$ per eent. $2 *$ 
Sugar-beets sent from other parts of the State; the sceds were furnished by Pres. Clark from those used on the College farm.

Nov. 7th. Hon. S. Williston; East Hampton, Mass.

Roots with tops; somewhat withered when tested.

$$
\begin{array}{cccc}
1 & \text { pound } & 6.5 & \text { ounces. } \\
2 & 4 & 11.25 & 66 \\
2 & 16 & 14 . & 6 \\
-6 & \text { " } & \frac{1575}{6} \\
\text { Juice; } & 12.39 \text { per cent. sugar. }
\end{array}
$$

Nov. Ioth. Dr. N. Durfee, of Fall River, Mass.

Roots with tops.

\begin{tabular}{lllll}
2 & pounds & \multicolumn{2}{c}{$\frac{1}{2}$ ounce. } \\
1 & 66 & 9 & 66 \\
2 & 66 & 5 & 66 \\
2 & 16 & 11 & 66 \\
\hline 8 & 66 & 9.5 & 6
\end{tabular}

Juice Brix $15^{\circ} 5^{\circ}$ at $16^{\circ} \mathrm{C}$.; Sugar $10^{\circ} 45$ per cent.

Nov. 22d. Wm. Knowlton, Esq., of Upton, Mass. Roots with tops (somewhat witherer.)

\begin{tabular}{cccc} 
I & pound & 10 ounces. \\
I & " & 4 & 66 \\
I & 6 & 11 & 66 \\
I & 6 & 10 & 66 \\
I & 6 & 12 & 6 \\
2 & 66 & 3 & 6 \\
I & 66 & 4 & 66 \\
\hline
\end{tabular}

1 i pounds 6 ounces.

Juice; Brix $15^{\circ}$ at $13^{\circ}$ C.; $10.07^{\circ}$ per cent. of sugar.

A large specimen of "The American Improved $1 \mathrm{~m}$ perial Sugar-Beet" of Hon. Henry Lane of Cornwall, Vermont, recommended for stock feeding, and raised at Williamstown, Mass., was tested at the request of Hon. P. A Chadbourne; the beet root had been on exhibition at the fair of the Hampshire Agricultural Society at Amherst, Sept. 27th, 1871, and was consequently in a somewhat dried up state; it was spongy, partly hollow, and weighed between 7 and 8 pounds; Juice, Brix $11.15^{\circ}$ at $14^{\circ} \mathrm{C}$; ; sugar 6.67 per cent. 
For the purpose of verifying the results of the optical analysis, I selected one of the best beet roots, the Vilmorin of Nov. 2 Ist, and subjected its juice to a chemical test. I took 100 c.c. of the juice prepared with a solution of subacetate of lead (one-tenth vol.) for the test with the polariscope, and precinitated the excess of lead by means of diluted sulphuric acid. I added then an excess of sulphuric acid and digested the mixture for several hours at a temperature of from $60^{\circ}$ to $80^{\circ} \mathrm{C}$. to convert the cane sugar into grape sugar, and neutralized subsequently with carbonate of soda and diluted the whole to 500 c.c. In two successive tests I noticed, that four c.c. of that solution sufficed to reduce twenty c.c. of Fehling's solution. These results prove, that 500 c.c. contain I 2.5 grammes of grape sugar, for 10. c.c. of Fehling's solution are equal to 0.050 grammes of grape sugar, or 0.0475 grammes of cane sugar. Adding to $12^{\circ} 5$ grammes one-tenth more for the dilution by subacetate of lead solution, we find that the original beet juice yielded 13.75 per cent. of grape sugar, or rather 13.09 per cent. of cane sugar, the form in which the juice contains its sugar. Similar results were obtained with the polariscope after the inversion of the cane sugar by means
of concentrated hydrochloric acid.

4. Determination of the solid residue of the juice.

I selected for this purpose a variety of sugar beet, which comparatively speaking, with a low percentage of sugar, had shown a high specific gravity of juice. Two different samples, each Ioo grammes of an Imperial sugar-beet juice (Nov. I 4th.), were evaporated carefully to dryness in an air bath, and the residue finally kept at from $100^{\circ}$ to $105^{\circ} \mathrm{C}$., until no further loss could be noticed. The solid residue varied from I $5^{\circ} .06$ to I $5^{\circ}$. 0 per cent. As the sugar found in that juice amounted to II 60 percent. we learned that its entire amount of organic and inorganic nonvolatile substances after the deduction of the sugar was equal to 3.40 per cent. The juice of that Imperial beet con-
sisted therefore of

Water 849 
These results from Brix's saccharometer and of the sugar tests, together, are usually turned to account to give some idea about the percentage of foreign matters in a beet juice, for instance in the case of the preceding examination we notice $15^{\circ}$ Brix as the specific gravity, the actual evaporation proves that each degree in that case corresponds quite closely with one per cent. of matter in solution.*

This assumption is not strictly exact, yet it gives for ordinary practice quite valuable indications. Subjecting then all previous investigations of beet juice to this mode of representing their value in a general way, we obtain the following figures:-

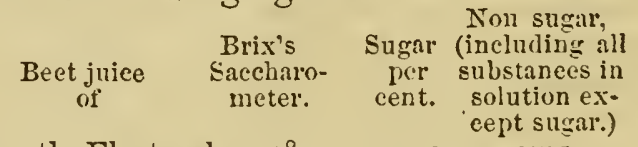

(1870) Sept. 1oth Electoral 14. $12.30 \quad 1.75$

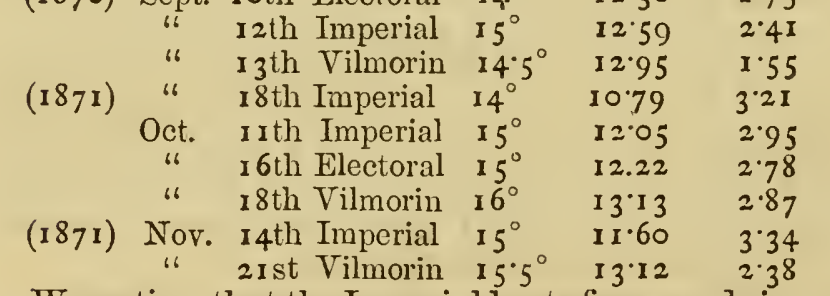

We notice, that the Imperial beets from seeds imported in $\mathrm{I} 87 \mathrm{I}$ differ considerably from the rest and are quite inferior to them; whilst the latter average very well, 12.63 of sugar to 2.38 non sugar or 100 parts of sugar to 18.8 non sugar, the inferior imperial stands on the average as II.I9 per cent. of sugar to 3.275 non sugar, or Ioo parts of sugar to $29^{\circ} 2$ parts of the others (non sugar).

The fodder beets differ still more as will be seen by the following statement:-

$\begin{array}{cccc}\text { Sept. I } & \text { Brix. } & \text { Sugar. } & \text { Non Sugar. } \\ \text { Commo Globe } & \text { II }^{\circ} & 8.00 & 3^{\circ} \\ \text { Common Mangold } & 9^{\circ} & 5.00 & 3.97\end{array}$

(Vienna) 100 parts of sugar to $37^{\circ} 50$ of other soluble substances.

$$
\text { and }
$$

(Mangold) Ioo parts of sugar to $79^{\circ} 50$ of other soluble substances.

* The Saecharometer used in my tests had for its smallest division one-half degree instead of one-tentl as would be desirable. 
5. Determination of the nitrogenous constituents of the beet juice.

Ioo grammes of the juice of an imperial beet (Nov. I 4 th), containing the largest proportion of foreign admixture in its juice, were used for this test, its solid dry residue amounted to I $5^{\circ}$ Io grammes. The analysis for the percentage of nitrogen was carried on in a Bohemian glass tube, and in the well-known manner with caustic soda and lime, taking particular care to apply a decided excess of that mixture to secure a thorough combustion of the highly carbonaceous mass. The ammonia resulting was collected by means of a moderately concentrated ( $I^{\cdot} I 2$ spec, grav.) hydrochloric acid in a Will-Varrentrapp apparatus and its amount determined in the form of platin-ammonium chloride.

I. 2.0660 grammes of dry pulverized residue of the beet juice produced 0.515 grammes of platin-ammonium chloride, which is equal to $3.76 \mathrm{r}$ grammes of the entire dry substance of the beet juice; again,

II. I.9I 2 grammes of the same residue produced 0.470 grammes of platin-ammonium chloride, which is equal to 3.6880 grammes of the entire residue. As 223.2 parts of the platinum compound contain 17 parts of ammonia or I4 parts of nitrogen, which is equal to 6.2724 per cent. of the latter, our results correspond to the following figures: $3 \cdot 761$ grammes of platin-ammonium chloride are equal to 0.2359 per cent. of nitrogen, and $3.688 \mathrm{I}$ grammes to 0.2315 of nitrogen. In case we assume that the whole amount of nitrogen found is present in the form of nitrogenous or albuminous substances, we may by multiplying the percentage of nitrogen found, by 6.25 , ascertain the amount of those compounds. The average of nitrogen found is $0.2337 \times 6.25=\mathrm{I} .460$ of albuminous substances. This assumption is, however, not exactly supported by facts, for the beet juice contains, besides the albuminous substances, two other nitrogenous compounds quite distinctly differing from the former, 
namely, asparagin* and betain, organic bases for which due allowance of nitrogen has to be made, which very naturally reduces more or less the amount of albuminous substance previously calculated. The albuminous substances generally vary in a good sugarbeet juice from $\mathrm{I} \cdot 3$ to $\mathrm{I} \cdot 4$ and the amount in the juice from beets raised upon the college farm cannot exceed that. It was deemed important to ascertain how much of these substances can be removed from the beet juice by means of an ordinary defecation or clarification in the course of the beet-sugar manufacture. In making these tests, it seemed necessary to treat the juice from two different varieties of sugar beets, yet raised upon the same field and under identical conditions.

Two hundred grammes of the juice from the Electoral sugar beet (October 16th) were heated quickly yet carefully in a glass flask to $80^{\circ} \mathrm{C}$., when two grammes of caustic magnesia (free from lime) were added with thorough stirring after the removal of the glass from the source of heat applied. The mixture was then heated again, without unnecessary delay, until the steam formed at the bottom began to force its way through the solid curdy scum upon the surface of the liquid. After having kept up the temperature to from $95^{\circ}$ to $98^{\circ} \mathrm{C}$. for about ten to fifteen minutes, the mixture was placed upon a weighed filter, and the solid residue left upon the filter after the filtration subsequently washed with 200 c. c. of distilled water at ordinary temperature before drying. The residue, after desiccation in the air-bath at $100^{\circ} \mathrm{C}$., weighed 4.776 grammes, which is equal to $2 \cdot 388$ per cent. An analysis of $2 \cdot 388$ grammes witl caustic soda and lime produced 0.6172 grammes of platin-ammonium chloride, which being equal to 0.0387 per cent. of nitrogen, shows that but 0.2346

* Asparagin was discovered in beet juice as early as 1850 by Dubrunfaut. Betain, a new organic base, was first noticed by Scheibler in 1869 . He found that the juice of beet roots, during the month of July, contained one-fourth per cent., while, in the month of October, but one-tenth per cent. was present. Scheibler has since proved the identity of the oxyneurin of siebreich and anhydrons betain, which can therefore be made directly by treating trimethylamin with monochloracetic acid. Betain has the formula $\mathrm{C}^{5} \mathrm{H}^{11} \mathrm{NO}^{2}$. 
per cent. of albuminous substances have been precipitated by heat and caustic magnesia.*

Two hundred grammes from the juice of the Vilmorin beet (October I 8th) wre treated with two grammes of caustic lime in the same way as in the preceding test with caustic magnesia. The caustic lime being to a much larger degree soluble in a solution of sugar than the magnesia, only 3.849 grammes of dry precipitate were obtained. 1 '9250 grammes of that residue produced 0.5060 grammes of platinammonium chloride, which is equal to 0.1923 per cent. of albuminous substances. Comparing the results of these tests, we notice that in the case of caustic magnesia nearly one-fifth more of nitrogenous substances was rendered insoluble than in the case of caustic lime, while in both cases but a small fraction (one-fifth to onc-sixth) of these compounds is rendered insoluble.

\section{Detormination of the Aste Constituents of the Bect Juice.}

The beet juice produced by the press contains more saline compounds than the press-cakes left behind, while the ashes of the latter contain more carbonic acid than those of the former. In both cases, the carbonic acid originated from the destruction of organic substanees. How much the mode of abstracting the juice from the sugar beets affects the quantity and quality of the saline constituents of the beet juice, I have already sufficiently pointed out and illustrated by analytical statements in my previous report. The various kinds of fertilizers applied are also known, as stated before, to affect the relative proportion of the various saline constituents of the press juice to some limited extent, and in a manner previously explained, yet the total amount absorbed, even in the case of the Stassfurt salines, varies but little, provided the soil is not overcharged with organic and particularly with nitrogenous organic plant-food. $\Lambda$ good sugar beet contains always at

* See Contribution on the Manufact re and Refining of Sucar, by C. A. Goessmann, Syracuse, is64; also, Chemical News, by W. Cruokes, London, 1864 . 
least three times as much potash as soda, and often even a larger proportion, but excessive applications of common salt as a manure are known to increase the relative amount of soda. The following inorganic constituents are usually found in the juice of the sugar beet, viz. : potassa, soda, lime, magnesia, iron, phosphoric, sulphuric and silicic acids and chlorine. Of these, the alkalies are of main importance so far as the sugar question is concerned, for they exert a specific intluence on the results of our ordinary modes of manufacture. Their great solubility, and their peculiar indifference towards the absorbing property of boneblack carry them largely as an obnoxious feature through all the operations down to the molasses. Only the determination of the potassa and soda is for this reason a quantitative one, whilst the remaining saline compounds are stated collectively as percentages of the ash constituents.

Five hundred grammes of Vilmorin (October I 8th) bect juice were carefully evaporated and gradually charred, until no vapors arose, and the compact, hard, carbonaceous mass was subsequently kept at a low red heat until it formed a very friable mass. The latter, after cooling, was finally ground, and for some time digested at ordinary tenperature with distilled water to prevent as much as possible a mutual decomposition of the ash constituents. After the mass had been digested for some time, it was placed upon a suitable filter, and subsequently washed with cold water, making the entire amount of the solution about $500 \mathrm{c}$. c. This solution, after its evaporation to dryness, and a re-solution, etc., left 0.928 grammes of alkaline compounds or 0.185 per cent. A direct examination proved that it contained 0.0762 per cent. of potassa and o.or 2 per cent. of soda. Against this mode of proceeding, I am aware it may be said that its results are not strictly exact, as traces of alkalies will pe left behind in the carbonaceous mass, but it appeared to me that the risk of a trifling loss was less serious than that caused by excessive heating to destroy the carbon.

One humdred grammes of Imperial beet juice (November 2oth) were carefully cvaporated and 
charred. The carbonaceous mass was then mixed with concentrated sulphuric acid and heated in a platinum dish to oxidize the carbon. This operation was repeated until no carbon could be noticed, and the residue moistened again with sulphuric acid was brought to a dull red heat, and subsequently weighed. It amounted to 1.273 grammes or I.237 per cent. Making the customary allowances for sulphuric acid (one-tenth of the weight of the saline residue) we find the entire ash constituents of the juice equal to $I \cdot I 5$ per cent. The amount of salines in the beet juice is, of course, much larger on account of the presence of the organic acids than the ash percentage represents.

I stated before that the amount, and particularly the kind of saline constituents in the beet juice is of great importance to the beet-sugar manufacture, for their amount even under favorable conditions is considerable, and they interfere more or less directly and indirectly with an advantageous separation of the sugar in well-developed crystals, and not unfrequently increase the amount of molasses at the expense of the sugar. The manufacturer feels thus obliged to direct his attention very carefully during the entire process of manufacture towards this point. He finds it for his interest to begin operations with a sugarbeet root having a small percentage of saline compounds, and supplies himself with water which contains but a small amount of mineral matter.* $\mathrm{He}$ removes the alkalies by washing from the caustic lime before using it for defecation, and strives also to remove every cause which might bring about such changes as will render the juice acid or induce the formation of acids, for they favor the introduction of otherwise insoluble compounds into the sugar solution, such as sulphate, phosphate and carbonate of lime, etc. Finally, he avoids the use of any organic or inorganic substances for the clarification of the-sugar

\footnotetext{
* Stammer states that, in case of the press mode being used, every rco pounds of beet-roots require 62 pounds of water; in case the maceration and diffusion modes are to be applied, from ISo to 200 pounds of water are needed usually for cvery 100 pounds of beets, provided white sugar is to be made.
} 
solutions which, in consequence of their own composition, are liable to increase the amount of soluble salines present. The means by which these compounds may be removed are costly, and, in regard to the alkalies in particular, very inefficient. Although the frequently cited statement that I per cent. of ash constituents will render from 4.5 to 5 per cent. of a good sugar uncrystallizable is not true in its generai application, yet sufficient is known to justify the assertion that their presence is highly objectionable. Some salines, as caustic potassa and soda, carbonate of potassa, acetate of potassa, and a few other combinations of the latter base with organic acids, are known to prevent directly more or less sugar from crystallizing, whilst the others, collecting in the molasses to a considerable proportion, increase its bulk and thus indirectly cause the retention of more or less sugar in a form of low value. Beet molasses contains about 45 to 50 per cent. of sugar and from 9 to 10 per cent. of ash constituents, the latter representing in all probability more than twice their weight of salines in the original solution, where the bases are combined with several organic as well as mineral acids.

\section{III.-ON THE SEPARATION OF THE SUGAR.}

The juice of the sugar-beet for the manufacture of sugar is secured in various ways. The roots, after being freed from the leaves, are washed and their tops cut off as far as the leaf marks extend; they are subsequently changed by means of suitable apparatus either into pulp, and in that state subjected to the action of a powerful press or centrifugal apparatus, or both operations successively; or they are cut into suitable slices and macerated or subjected to a process of diffusion. Each mode of operation quite naturally affects to some extent the quantity, the kind, and the relative proportions of the constituents which accompany the sugar in the resulting juice. No one of these modes produces a solution directly fit for the separation of the sugar by its mere evaporation and subsequent crystallization. Any of these juices in their original state soon turn slimy, and 
their sugar will soon become uncrystallizable, and thus be entirely lost to the manufacturer. All have, therefore, without delay to undergo a similar process of purification before an advantageous separation of the sugar can be expected. It may be of interest to state here somewhat more in detail the main organic and inorganic constituents of the beet-juice; they are cane sugar, pectose, fat, gum, protein substances, asparagin, betain, oxalic acid, citric acid, and extractive matter (a collective name for organic substances but little known), besides potassa, soda, rubidium*, lime, magnesia, iron, manganese, phosphoric acid, sulphuric acid, chlorine and silicic acid. As the various constituents of the beet-juice, obtained by pursuing any of the previously mentioned modes of separation, are either identical or at least of a similar character, and as they mainly differ in regard to their relative quantities, the same general mode of manufacture with but slight modifications is practised for the final separation of the sugar.

Instead of inserting here a chapter treating on this point more in detail, I prefer to confine myself for the present to the task before me, and to describe the way by which I ascertained the amount of sugar, which could be considered available for commercial purposes. In the course adopted, I adhered as much as possible to the modes and the means which intelligent beet-sugar manufacturers apply, and modified my plan merely to suit the peculiar circumstances under which I was obliged to work.

I took fifty pounds of Electoral beet juice (October I 8th), in a suitable copper kettle and heated it quickly but carefully to $80^{\circ} \mathrm{C}$. to produce the coagulation of the albuminous substances. I then removed the vessel from the source of heat and stirred into the liquid one-half of one per cent. of caustic lime, which had been changed into milk of lime. The heat was then

* Lefevere states that one hectare ( 2.5 acres), which produces on th $\mathrm{e}_{3}^{\mathrm{e}}$ average 40,000 kilogrammes $(88,000$ lbs.) of sugar beets and furnishe at the same time 128 kilogrammes $(28 \mathrm{I} \cdot 6 \mathrm{lbs} .$, ) of crude potash, contain $\mathrm{e}$ for every kilogramme of the latter $x^{\cdot 75}$ grammes of liubilium chlorid or 288 grammes per hectare or $91^{\prime} 5$ grammes per acre (Compt. rendus T. LIV, page 430. I862.) 
applied again and the liquid rapidly raised to its boiling point, and as soon as the steam produced at the bottom of the vessel began to force its way through the compact mass of scum covering the surface, the heat was discontinued and the clear liquid was separated from the scum, after ten to fifteen minutes standing, by means of a siphon. The scum itself was subsequently placed upon a filter consisting of cloth and the filtrate passed through a thin layer of coarse boneblack to render tlie juice clear. The previous treatment of the juice of the sugar beet, which is called the process of defecation, aims at the following alteration of its constituents. The heating of the juice at $80^{\circ} \mathrm{C}$. cartses the coagulation of the albuminous substances which protects them somewhat against the disintegrating reaction of the caustic lime, and particularly of the caustic potassa and soda, which result from the action of the caustic lime upon the organic and inorganic compounds of these alkalies in the beet juice. The excess of caustic lime renders, at a higher temperature, the oxalic acid, the citric acid, and the phosphoric acid largely insoluble, and causes thus their partial removal in common with gum, fat, pectose, and extractive substances in the form of a precipitate. The asparagin is changed into asparaginic acid and ammonia, which continually escapes, with that amount of the latter which results from the constant decomposition of a portion of nitrogenous substance which remained in solution. The organic base, betain, is liberated from its combination with one of the organic acids, and, being very soluble, accompanies the larger proportion of the compounds of the asparaginic acid and the alkalies through the various operations connected with the crystallization of the sugar into the molasses. The sugar forms a definite soluble combination with lime, and by its presence keeps also a large amount of otherwise insoluble lime compounds in solution.* There are various rules regarding the amount of caustic lime required to accomplish the desired result of an

* A well defecater juice contains about twice as much caustic limo in solution, as lime water does. 
economical separation of the sugar from its accompanying substances, but they all aim at an excess of caustic lime in the process of defecation. The excess favors the formation of insoluble basic lime compounds, the subsequent disintegration of soluble albuminous substances, and particularly it shortens the entire process of defecation, a result most desirable for the production of a copious precipitation, which would be more or less interfered with in case the liberated alkalies were permitted to continue their disintegrating influence upon the scum for any length of time. A successful defecation, considering everything else equally favorable, aids in an unusual degree the entire subsequent process. To remove the foreign substances from the beet juice rather by precipitation than by disintegration ought to be the aim of the beet-sugar manufacturer, yet those who claim superior results (Jelinske) it seems remove but fifty per cent. of soluble non-saccharine constituents of the juice. No other process connected with the beet-sugar manufacture has been more frequently discussed than that of defecating the juice, and there prevails a greater diversity of opinion among manufacturers on that point, with the exception probably of the most efficient and at the same time the most economical means of securing the juice from the roots, than on any other point connected with the business.

The defecated juice, obtained as above described, was of a light yellow color, transparent and of a strong alkaline reaction. To secure the full effect of the lime in solution, I concentrated the juice in an open copper vessel by means of a steam bath to $30^{\circ}$ Brix, and treated it at $50^{\circ} \mathrm{C}$. with carefully washéd carbonic acid gas until the precipitate of carbonate of lime settled readily to the bottom.* The clear solution was heated to $95^{\circ}$ to $100^{\circ} \mathrm{C}$. and subsequently passed through a boneblack filter, which was kept by means of steam at $95^{\circ} \mathrm{C}$. I used one pound of boneblack for every pound of sugar in the juice. The solution thus obtained was carefully evaporated to

* From 0.08 to 0.09 per. cent. of caustic lime is frequently left in solution to be removed by bone-black afterwards. From to to $20 \mathrm{lbs}$. or hone-black are used for erery roo lbs. of beet ronts. 
crystallization and the sugar collected at three different times. It amounted to somewhat more than eight per cent. with separation still going on slowly. The operation was several times repeated with the juice of the Electoral, and of the best Imperial beet, and the sugar resulting was firm in grain and of good color. Experiments on a smaller scale yielded from a juice which contained I 3 . I 9 per cent. of sugar, 9.4 per cent. in a crystallized form, which has been valued by experienced sugar refiners at from $8 \cdot 5$ to 9 cents per pound for refining purposes. Being obliged to work without a vacuum pan, \&c., and obtaining as stated eight per cent. of a good sugar worth at least eight cents per pound, I feel quite entitled to say that the sugar beets raised upon the college farm, particularly the Vilmorin and the Electoral, though not of the highest order, are well qualified for the economical manufacture of beet sugar. With proper care in selecting good seeds and a fit soil, it is quite apparent that the sugar beet promises with us as good results as in Europe. Our long and moderately warm fall season may even give us a decided advantage over many localities in Europe, a question which good native sugar beets are most likely soon to decide.

Our method of planting the sugar beet did not promise more than 18,000 plants per acre, which according to our actual test produced roots equal to about one and one-fourth pounds each. In case the implements on hand would have allowed to carry out the proposed arrangement (the rows but twenty inches apart and the individual plants eight inches from each other in the rows), from 28,000 to 28,500 plants might have been raised, which at the same average weight of the roots would amount to 32,000 or 34,000 pounds per acre. At this rate of production, it is quite safe to say that from I, 900 to 2,000 pounds of sugar would be its produce per acre. These figures, which are as will be conceded well supported by actual tests here and elsewhere, oblige me to alter the valuation of the produce per acre from that of my first report. For obvious reasons, I adopt here again rather the lowest rates than the higher ones, although the field on which the experiments were 
made, was by no means equal in fertility to the alluvial soil of the Connecticut.

Sugar, I,900 pounds at eight cents per pound, $\$ 152.00$

Molasses for teeding purposes, . . . 3.66

Press-cakes, $\$ 17^{\circ} 40$, crowns, $\$ 4^{\circ} 00$, . . $21^{\circ} 40$

Leaves, as manure or fodder, . . . 12.00

$\$ 189.06$

To this amount should be added the profit on fodder converted into milk, beef and manure.

Making allowance for exceptionally good results, which are in Germany, for instance, 2,270 pounds of sugar per acre, $\$ 29^{\circ} 60$ would have to be added to the above sum. Adding one cent to the value of each pound of sugar, which considering our present market prices seems to be warranted, would be $\$ 15.20$ more, making the entire yield $\$ 222.86$ per acre. There are, also, incidental profits arising in the manufacture of sugar, which benefit particularly the agricultural interest, which were not enumerated in my former report. Two sources of additional profit deserve particular attention here. The process of defecation requires the application to the juice of from one to several per cent. of caustic lime. The scum resulting from this operation contains a large percentage of phosphoric acid, magnesia, nitrogenous and non-nitrogenous organic constituents of the beet juice, a considerable quantity of caustic and carbonate of lime, and these are in such a state that they may serve, after some composting, as an (fficient fertilizer. In its original condition, it consists of about 60 per cent. of water, 22 per cent. of organic substances, and 18 per cent. of inorganic substances, and has been counted in this state equal to its own weight of stable manure. This mass is frequently pressed to save sugar, and varies of course somewhat in its composition. One acre of beet-roots causes the production of about 750 pounds of pressed scum of the following composition : 
Caustic and carbonate of lime,

Potassa and soda,

Magnesia,

Phosphoric acid, $:$

Sulphuric acid, : : :

Nitrogen,

Organic substances, :

Water, . . . :

254.80 pounds.

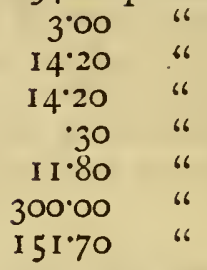

$750^{\circ} 00$ pounds.

- The refuse matter (spodium), resulting from the clarification and decolorization of the sugar solution, is also worth mentioning in this connection, as an important source of an excellent material for the manufacture of super-phosphate. The peculiar benefits which the agricultural interests of a country derive, directly or indirectly, from the introduction of the beet-sugar industry, under judicious management, have never been seriously questioned. I express but the prevailing opinion of European agriculturists, when I again assert, that wherever the promotion of rational principles in agricultural pursuits is a desirable object, or where a declining productiveness of the soil calls for efficient assistance, there it will be found of inestimable service to study the ways and means by which the true relation of the various farm crops to the sugar beet have been ascertained, and the beet-sugar manufacture rendered a lucrative agricultural and industrial business.

The great interest which of late has been manifested throughout the entire country in regard to the introduction of the beet-sugar manufacture, is a sufficient proof that its importance begins to be realized. The question has reached in the minds of many already a state which leaves no further choice for arguments than the laboratory, the field and the factory. We have, in many respects, an easier task and less discouraging prospects, when contemplating the introduction of the beet-sugar manufacture, than those who began this enterprise years ago in Europe. They had first to find out how to raise a good sugar beet, and how to separate in an economical way the sugar, whilst we may, simply, for the present, follow 
their teachings, ascertain the results upon our 'soil, and modify their methods to suit our circumstances. They were not less confronted by the same difficulties in their time, which are held up to us as great obstacles in the way of success, namely; an uncertain degree of prituction for a struggling home industry and too expensive labor by hand to complete with the colonial sugar produce of the West and East Indies. Their times were indeed hard and their chances* frequently doubtful; yet in looking closer at their struggle, we cannot help noticing that the very circumstances which seemed at times to render success impossible, have contributed largely to a final good result. A firm belief in the advantages offered by a rational mode of cultivation and by skilled labor over mere empirical routine, carried them successfully to the end. How well they succeeded may be inferred from the following two facts: first, most of the sugar refineries which in former years were engaged in refining sugar from the sugar cane of the tropics, are now refining home-made beet-sugar ; secondly, the introduction of numerous mechanical contrivances has reduced expensive hand labor in the field and in the factory, to a condition which compares very favorably with the relative amounts of machine and hand labor employed in similar industrial operations. Nothing remains for us to do but to enter upon a close investigation of the merits of the question. A study of our resources with reference to the important changes which have taken place in the management of the beet-sugar industry within later years cannot but demonstrate that the prospects are promising. The chief argument used against the introduction of the beet-sugar manufacture as a lome industry, rests to-day solely on the expensive fieldwork which is required to till and to manure the soil properly to cultivate the beet root according to the

\footnotetext{
* From 1836 to 1846 about 2000 pounds of beet roots were required to produce 1oo lbs. of sugar ( 5 jeer cent.); from 1846 to 1856 about 1500 lbs. of beet roots to produce $100 \mathrm{lbs}$. of sugar ( 6 t per cent.); from 1856 to 1868 about $1250 \mathrm{lbs}$. of beet roots for $100 \mathrm{lbs}$. of sugar ( 8 per cent.) The government tax is thirty times bigher in Germany and France on the beet root than in 1840 .
} 
best rules, and to deliver them at the mill. Although duly recognizing the great weight of this point, for with the farmer rests the success of the enterprise in the end, I believe that its influence as an obstacle is frequently overrated and based on some hat obsolete assumptions. The government tax of from $\$ 40$ to $\$ 50$ per acre of sugar beets, in Germany and France, as well as our higher prices of sugar, will go far towards covering our more expensive labor.* The interests of the Louisiana sugar planters, and the sugar-beet cultivators of more northern sections of the country are the same, as far as a proper protection of their industry is concerned; and the public opinion, in view of the requirements of the government, is apparently prepared to accord to them, for some time, at least, this advantage. Great improvements in agricultural implements, and in modes of securing the juice, have reduced labor by hand to a considerable extent. A short enumeration of the most conspicuous instances may place this statement in its proper light. Various seeding machines, improvements more or less on Garrett's famous seed-drill, are used in planting the seed in four or more rows at once, and at any desired distances from twelve to twenty inches apart. According to the size of the machine, one or two men with one or two horses or oxen, may seed from eight to sixteen acres per day; the same implement can also be modified, by replacing the seed boxes with suitable knives to be used as cultivators, to clean the space between the rows of plants and to cover the roots. Ploughs with two knives are used to break up the soil on both sides of the rows of beets, to loosen the latter in such a manner, without lacerating them, that children may do the harvesting of the roots. In fact, the whole work in the field, after the soil is once properly broken up, calls for no extraordinary labor. A good deal of the work can be done by boys. Machines do the washing, the grinding or cutting, and general handling of the

\footnotetext{
* The average price of the best quality of loaf sugar (crushed) from sugar beets was in Germany during the years $1868-59$, but 11 ' per Ioo pounds.
} 


\section{5}

roots to the centrifugal apparatus. The task of handling the pulp of beet roots for the press requires, comparatively speaking, a large supply of hands to do the business connected with that process, but Roberts' diffusion method dispenses with a large number of the hands formerly required in the pressroom-nearly one-half.

A report concerning the influence of Roberts' method on the financial results of an establishment which formerly used the press mode for obtaining the beet juice may illustrate the previous statement, and at the same time give some clearer idea about the importance of the labor question, as far as its relative bearing on the financial success of the entire manufacturing operation is concerned. 200,000 pounds of beet roots needed per day (twenty-four hours' actual work) in the press-room, eighteen men, fifty-two girls and twenty-eight boys to perform the handling of the pulp and cakes, whilst after the introduction of the diffusion mode of Roberts, but twentysix men and ten boys attended to the separation of the juice. The saving of one-half the expenses in that department during a campaign of one hundred and fifty days amounted to much, yet in summing up the entire gain due to a change of operation, it is of some interest to notice that but one-sixth of the extra earnings of the manufacturer was caused by saving in the expenses of labor. I call attention to this instance. to show that an extra cost of hand labor does not affect after all the chances of success to such a degree as is frequently asserted. The margin for profits is larger here than in many other branches of business. The real success of the beet-sugar industry, in its present high state of devclopment, depends, in $\mathrm{my}$ opinion, with us far more on an intelligent and close attention to the details of its various operations in the field and in the factory than on any other requirement.*

* My particular thanks are due to Messrs. John E. King and John B. Minor, students of the College, for valuable assistance rendered during my investigations. 




\section{THE AMERICAN CHEVIST.}

A Monthly Journal of Theoretical, Analytical, and Technical Chemistry. Eilited and published by CHARLES F. CHANDLER. Pl. W. Professor of Analytieal and Applied Chemistre, in the school of Jines. Colmmbia College, and WILLIAM H. CHANIILE. Professon of Cilemistry in the Lehigh University, at Bethlehem, Pal.

With the assistance of M. Alsberg. Ph. D., Prof. G. F. Barker, T. M. Buosson, E. M. H. C. Button. Ph. D., Prof. T, Eilestun, F. M. H. Exdemaxx. Ph. D., Prof. C. A. Goessmanx, Pur. D., Prof. C. A. Joy, Ph. D.. J. P. Krmball, Ph. 1)., H. Newtox, E. M., Prot. Frederick Primf, JP. Paul Srilteitzer, Ph. D., Waldrox SilapLFIGII, A. C., and ElWiN WaleEr, Li. $M$.

This Journal is the medium of communication for the chemists of the country : not only those who are engaged in theoretical investigation, but also those who are clevoted to the practical application of chemistry to the arts.

The American Chemist is published in monthly numbers, each number eontaining forty double column quarto pages of reading matter.

It contains original Articles; Reprints and Transla tions of the most important Articles published in this and other countries: Reports of Chemical Lectures; Abstracts of all original Articles on Chemistry which are published in other. Journals, and in the transactions of Learned Sorities; Notices of Boolss; Lists of Chemical Patents granted at TWashington; Current News relating to Chemists and to Chemistry; Questions from, and Answers to Correspondents.

It is the intention of the Elitors to place before its readers everything that will be of interest to Chenists and those who are engaged in Chemical Pursinits.

To this end arringements iave becu made by which over one hundred different Journals are now reecived regularly, from England, France. Relgrmm, Italy, Germany, Russia and America, and carelully examined for the benefit of its reader's.

Send sicts. for Specimen Copy.

Subscription, $\$ 5.00$ per annum, in advance; $50 \mathrm{cls}$ per number.

Address C. F. \& W. H. CHA NDLER,

School of Mines, Columbia College, 49 th St., Cor. 4 th Av., New Tork. 